Derecho \& Realidad

Núm. 24 • II semestre de 2014

Facultad de Derecho y Ciencias Sociales, UPTC

ISSN: 1692-3936

\title{
Neoliberales en América Latina. Ortodoxos $y$ convencionales
}

\author{
Neoliberals in Latin America. \\ Ortodox and conventional
}

Claudio Katz

\section{Resumen}

En América Latina el neoliberalismo comenzó antes y ha enfrentado mayores resistencias. Es una práctica reaccionaria, un pensamiento conservador y un modelo de acumulación basado en agresiones a los trabajadores, en un marco de mayor internacionalización del capital.

Hubo una etapa inicial del ajuste y otra fase posterior de privatizaciones durante las dictaduras y las transiciones posteriores. La aplicación del esquema neoclásico acentuó los desequilibrios financieros, cambiarios y productivos tradicionales y repitió los socorros estatales a los capitalistas a costa del erario público.

A diferencia de otras regiones, el neoliberalismo latinoamericano quedó afectado por el impacto de las sublevaciones populares. Mantiene el programa derechista, pero redujo su triunfalismo, atenuó sus ambiciones y acepta cierta intervención estatal. Puede ser visto como etapa del capitalismo, estrategia de libre-comercio, política económica o gobierno derechista. Para definir si se encuentra a la ofensiva o en repliegue hay que distinguir esas cuatro acepciones.

* Economista, investigador, profesor. Miembro del EDI (Economistas de Izquierda). Su página web es: www.lahaine.org/katz 
El librecambismo postula una imaginaria inserción natural en el mercado mundial y reproduce el subdesarrollo que genera la exportación primaria. Las brechas internacionales de productividad desmienten las fantasías de convergencia entre economías avanzadas y periféricas.

El neoliberalismo hereda viejas teorías de inferioridad de los nativos, atraso cultural hispanoamericano y supremacía de Occidente. Retoma los mitos positivistas de la modernización basados en la copia del capitalismo avanzado. Despotrica contra la injerencia estatal, ocultando los beneficios que obtienen los capitalistas y no explica la continuidad de esa intervención al cabo de tantos gobiernos pro-mercado. Es absurda su presentación de la informalidad laboral como una resurrección de la competencia empresaria.

Como creencia, programa o cosmovisión el neoliberalismo es la principal ideología actual de las clases dominantes. No ha sido internalizada por los oprimidos.

\title{
Palabras clave
}

Neoliberalismo, internacionalización del capital, libre-comercio, privatizaciones.

\begin{abstract}
In Latin America the neoliberalism began earlier and has faced greater resistance. It is a reactionary practice, conservative thinking and accumulation model based on attacks to workers, in a context of greater internationalization of the capital. There was an initial stage of adjustment and another phase of privatizations during the dictatorships and the subsequent transitions.
\end{abstract}

\section{Keywords}

Neoliberalism, internationalization of capital, free trade, privatization. 


\section{Introducción}

¿Cuáles son las peculiaridades del neoliberalismo en América Latina? ¿Alcanzó mayor penetración que en los países centrales? ¿Registra un declive superior al resto del mundo?

Es sabido que esta modalidad reaccionaria fue introducida en la región con cierta antelación. Las dictaduras del Cono Sur anticiparon en los años 70 la oleada derechista, que posteriormente se afianzó en el grueso del planeta. Pero Latinoamérica ha sido también el epicentro de grandes resistencias populares, que propinaron significativas derrotas a ese aluvión conservador. Una revisión de la trayectoria e ideología del neoliberalismo permite explicar muchas especificidades de la región.

\section{Caracterizaciones generales}

Las primeras discusiones internacionales sobre el neoliberalismo destacaron las raíces teóricas de esta corriente en el pensamiento económico neoclásico. También explicaron su aparición por el agotamiento del crecimiento keynesiano de posguerra y resaltaron sus objetivos políticos regresivos. El neoliberalismo fue definido en los años 80, como una ofensiva del capital sobre el trabajo para recomponer la tasa de ganancia (Hirsch, 1999).

En la década siguiente se constató la hegemonía ideológica mundial alcanzada por esta vertiente. A pesar de los magros resultados económicos logrados durante ese decenio, la derecha se reforzó aprovechando el debilitamiento de los sindicatos y el desasosiego creado por la fractura social. El neoliberalismo expandió su influencia e implementó una drástica reconversión de la economía.

La expectativa en un rápido declive de esta corriente fue disipada por la implosión de la URSS y la crisis del horizonte socialista. Las tendencias conservadoras obtuvieron un impulso adicional con la anexión de Alemania Oriental, el amoldamiento de la Unión Europea a la globalización y la demolición del estado de bienestar (Anderson, 1995-1995,2003, 2009).

La crisis económica iniciada en el 2008 abrió grandes interrogantes sobre la continuidad del modelo privatista. Esta convulsión superó las conmociones financieras precedentes e ilustró la magnitud de los desequilibrios creados por el neoliberalismo. Pero la preeminencia de este ciclo se mantuvo (Harvey, 2005).

Su persistencia se ha verificado en todos los acontecimientos de la coyuntura 20082014. La etapa que comenzó con el thatcherismo transformó el funcionamiento del 
capitalismo mediante privatizaciones, aperturas comerciales y flexibilizaciones laborales. Este esquema intensificó la competencia global por aumentos de la productividad desgajados del salario, que amplifican todas las tensiones de la producción, el consumo y las finanzas.

En los últimos años este modelo profundizó los atropellos contra los trabajadores en contextos recesivos que potencian el temor a la miseria. La desigualdad social alcanzó niveles sin precedentes, la pobreza se expandió en las economías centrales y la precarización laboral se masificó en todo el planeta.

El neoliberalismo converge con la internacionalización de la economía. La fragmentación mundial de los procesos de fabricación, el desplazamiento de la industria hacia al Oriente consolidan la primacía de las empresas transnacionales. Las grandes firmas utilizan las normas del libre-comercio y los bajos aranceles para desenvolver intercambios entre sus filiales. Estos movimientos apuntalan, además, la globalización financiera y el vertiginoso flujo de capitales entre los distintos países.

Las transformaciones neoliberales han generando un modelo que opera con parámetros muy distintos al keynesiano de posguerra. Ese esquema desencadena crisis muy específicas, que ya no irrumpen como arrastres de viejos desequilibrios de los años 70. Al cabo de tres décadas de reorganización capitalista se han creado nuevas contradicciones en múltiples esferas.

El neoliberalismo contrajo los ingresos populares, afectó la capacidad de consumo, incrementó la sobreproducción de mercancías y agravó varias modalidades de sobreacumulación de capital. Acentuó, además, un deterioro del medio ambiente que amenaza desatar inéditos desastres ecológicos.

En el plano geopolítico este curso ha precipitado un rediseño de fronteras que contrasta con el congelado mapa de la guerra fría. Ya transitó por fases diferenciadas de bipolaridad, unipolaridad y multipolaridad en las relaciones que mantienen las grandes potencias. Pero todos los conflictos entre las clases dominantes se procesan en un nuevo marco de negocios globalizados.

El neoliberalismo perdura por el retroceso que impuso a los trabajadores. Se sostiene en el cansancio político que genera la alternancia de conservadores y socialdemócratas en la administración del mismo modelo. Todo indica que la reversión de esta etapa exigirá grandes victorias populares impuestas desde abajo (Katz, 2014).

En este escenario: ¿cuáles son las peculiaridades de América Latina? 


\section{Justificaciones y períodos}

A mitad de los años 70 el neoliberalismo latinoamericano anticipó todas las tendencias de los países desarrollados. Ese paradigma se forjó en Chile bajo Pinochet, con el asesoramiento económico ortodoxo de Hayek y Milton Friedman. Allí se experimentó la doctrina que posteriormente aplicaron otras dictaduras de la región.

Estos ensayos no se extinguieron con el fin de los gobiernos militares. El neoliberalismo fue convalidado por los regímenes constitucionales que sucedieron a las tiranías del Cono Sur. Esta continuidad afianzó las transformaciones estructurales introducidas por el modelo derechista.

La prioridad del neoliberalismo en la región fue desterrar la influencia alcanzada por la izquierda y el nacionalismo radical al calor de la revolución cubana. También arremetió contra la heterodoxia keynesiana de varios pensadores de la CEPAL.

Su cruzada contra las reformas sociales, la redistribución del ingreso y la defensa del patrimonio nacional signó todo el período de transición post-dictatorial. Con algunos cambios de formato fueron convalidadas las principales mutaciones regresivas impuestas por los militares.

En el plano económico el neoliberalismo latinoamericano atravesó por dos etapas diferenciadas. En los 80 prevalecieron las «reformas de primera generación» con prioridades de ajuste anti-inflacionario. En el decenio siguiente predominó el «Consenso de Washington» con transformaciones complementarias de apertura comercial, privatizaciones y flexibilización laboral.

En el primer período se introdujeron políticas de shock para recortar el gasto público social y elevar las tasas de interés. Estas medidas fueron justificadas con criterios neoclásicos de equilibrio, que realzaban la primacía del mercado en la asignación de los recursos (Nahon, 2006).

Estos postulados walrasianos fueron esgrimidos para exaltar el reinado de la oferta y la demanda y cuestionar la injerencia estatal. Todos los debates fueron encapsulados en conceptos neoliberales. Abundaron los estudios para mensurar el aporte de cada «factor» (tecnología, recursos naturales, capital humano) al crecimiento. Las evaluaciones de los procesos productivos fueron despojadas de sus fundamentos sociales y la enseñanza de economía quedó reducida a una indagación de relaciones funcionales entre variables inexplicadas (Olivera, 2010, p. 26-27).

La ideología neoliberal incentivó esa fascinación con la formalización y el tratamiento de la economía como un sistema mecánico, sujeto a los ajustes aconsejados por los 
Derecho ₹ Realidad

técnicos neoclásicos. Toda la tradición latinoamericana de estudios históricos-sociales quedó sepultada por el aluvión de especialistas llegados desde Washington y Chicago. El análisis de las contradicciones, desequilibrios o límites de la economía latinoamericana fue reemplazado por espejismos tecnocráticos.

En este clima se gestó la segunda fase neoliberal. Se afirmó que el saneamiento del escenario macroeconómico regional ya permitía abrir las compuertas de la eficiencia, desmantelando empresas estatales y eliminando protecciones arancelarias.

A partir de ese momento cobró más relevancia la vertiente austríaca de la teoría neoclásica. Las supersticiones en la mano invisible fueron complementadas con propuestas de darwinismo social competitivo. Se incentivó el remate de las propiedades del estado y la apertura masiva a las importaciones. Con el pretexto de restaurar patrones de riesgo, esfuerzo y productividad se propició la reducción de los ingresos populares y el aumento de la desigualdad.

El establishment transformó estos principios en un libreto de toda la sociedad. El mismo relato fue expuesto por los gobernantes, transmitido en las escuelas, enaltecido en las universidad y popularizado por los medios de comunicación. La organización ultra-liberal Mont Pelerin Society y sus Centros de Estudios de la Libertad (CDEL) introdujeron muchas ideas para esta contrarreforma.

\section{Crisis y fracasos}

Al comienzo del nuevo siglo irrumpió la crisis del neoliberalismo latinoamericano. Los desequilibrios generados por ese modelo salieron a flote en toda la región, junto a la creciente primacía del sector exportador en desmedro del desenvolvimiento interno. Aumentó la heterogeneidad estructural de la economía y se concentraron las actividades más rentables en un puñado de empresas. La capacidad del estado para priorizar las decisiones de inversión quedó muy debilitada (Vidal, 2007).

Las dos etapas neoliberales de ajuste y apertura no sólo deterioraron los ingresos populares. También provocaron la desintegración de la vieja industria local gestada durante la sustitución de importaciones. Se acentuó la vulnerabilidad de todas las economías ante la descontrolada afluencia o salida de capitales externos. También se intensificó la dependencia del vaivén internacional de los precios de las materias primas.

Las economías latinoamericanas volvieron a soportar la carencia estructural de divisas. No pudieron respaldar las reservas, ni mantener bajo control el tipo de cambio, la tasa de interés o el nivel de inflación. Cuando estos desequilibrios 
emergieron, los ministros pro-mercado abandonaron sus doctrinas y recurrieron al mismo endeudamiento que caracterizó a sus antecesores.

Todas las prédicas de ortodoxia fiscal, cuidado monetario y prudencia en la expansión de la deuda pública fueron archivadas. Se optó por el costoso crédito externo para lidiar con las asfixias generadas por el propio modelo. En muy poco tiempo los mitos del rigor neoliberal en el gerenciamiento del estado quedaron desmentidos. Esta política desembocó en la misma asfixia de pagos que ha jaqueado repetidamente a la región (Guillén, 2007).

Varios años de privatizaciones y flexibilidad laboral recrearon las crisis financieras, los quebrantos fiscales, las fugas de capital y los colapsos cambiario-monetarios del pasado. El desplome de la Argentina en el 2001 fue la expresión más dramática de esta repetición de viejas convulsiones.

El neoliberalismo mantuvo un bajo nivel de actividad económica. La ilusión en un repentino despegue por el simple efecto de políticas conservadoras quedó desmentida. El recorte de los salarios y del gasto social no incentivó la inversión. Tampoco las privatizaciones encendieron la mecha del crecimiento.

En todo el período estuvo ausente el esperado derrame de bienestar desde los acaudalados hacia el resto de la población. Sólo resurgieron los breves ciclos de mayor consumo de la clase media. Fue muy visible el acaparamiento de ingresos de los poderosos a costa de los trabajadores.

El balance del neoliberalismo es contundente en los propios términos de ese esquema. Pretendía revertir el bajo crecimiento y mantuvo un reducido nivel de expansión de la economía. Esperaba eliminar las crisis financiero-cambiarias y agravó esos desmoronamientos. Prometía erigir una plataforma duradera de inversión y acentuó la distancia de la región con los países que incrementaron su desarrollo.

Los intentos de remontar estos fallidos con alguna dosis de la misma medicina terminaron precipitando las crisis mayúsculas de principio de siglo XXI. Estas convulsiones confirmaron que las clases dominantes atropellaron las conquistas populares, sin convertir esos éxitos capitalistas en procesos sostenidos de acumulación (Katz, 2008, p. 9-35).

Los propios impulsores del liberalismo extremo quedaron defraudados por un retroceso económico que deterioró la incidencia de América Latina en el mercado mundial. La cohesión política inicial del proyecto derechista se diluyó y el modelo afrontó su desafío más directo a partir de las sublevaciones populares de 1999-2005. 
Derecho ₹ Realidad

\section{Rebeliones y virajes}

El neoliberalismo latinoamericano fue socavado por levantamientos sociales parcialmente exitosos. Este resultado determinó la principal singularidad de este proyecto en la región. Las protestas pusieron un límite a la ofensiva del capital, especialmente luego de cuatro alzamientos victoriosos (Argentina, Bolivia, Ecuador y Venezuela) que tumbaron a los artífices del ajuste.

Las rebeliones no alcanzaron la envergadura de las revoluciones del siglo XX, pero modificaron las relaciones de fuerza y forzaron concesiones sociales que contradicen el programa de Thtacher-Hayek. Estas conquistas erosionaron el plan de la reacción y generaron un escenario que diferencia a Sudamérica de otras zonas con predominio neoliberal continuado (Katz, 2008, p. 9-35).

En este nuevo marco la derecha ajustó su estrategia e introdujo una variante más moderada del mismo modelo. Este curso incluye discursos éticos, cierta intervención del estado y alguna sintonía con la síntesis neoclásico-keynesiana de posguerra (Herrera, 2010, p. 23-24).

La retórica que adoptó el Banco Mundial es muy representativa de este cambio. Los promotores del ajuste han edulcorado sus recetas y esgrimen una hipócrita preocupación por la pobreza. Reconocen las «fallas de mercado» y promueven alguna regulación del estado parar corregir los excesos de la concurrencia (Burkett \& Hart-Landsberg, 2003).

Los informes de los organismos internacionales ya no presentan la radicalidad neoclásica de los años 80 o 90. Reconocen las imperfecciones mercantiles y destacan la primacía de la acción estatal en ciertas áreas (medio ambiente, capital humano, infraestructura). Estos mensajes combinan el acervo ortodoxo con la intervención pública y proponen nuevos remedios para las rigideces de los precios y las trabas en la circulación de la información.

Este neoliberalismo más atenuado también remarca la importancia del asistencialismo. Acepta el gasto público para contener la explosión de pobreza, como un precio a pagar durante la transición en curso. Supone que esa erogación será pasajera y se extinguirá cuando el modelo genere más empleo. En los hechos registra el enorme impacto de grandes sublevaciones que atemorizaron a los capitalistas.

El neoliberalismo del siglo XXI ha morigerado su entusiasmo inicial con la globalización. Ya no transmite el espíritu triunfalista de «fin de la historia» que anunciaba Fukuyama, ni se vanagloria por las «victorias de Occidente». Acepta la 
existencia de una mayor variedad de caminos al bienestar que la simple imitación de Estados Unidos o Europa.

También destaca la incidencia de los valores imperantes en Oriente que facilitaron los despegues de China y el Sudeste Asiático. Resalta la centralidad cultural de la comunicación global y subraya su novedosa influencia para incentivar el desenvolvimiento de la periferia.

El neoliberalismo actual ha incorporado además varias teorías de crecimiento endógeno, que realzan la necesidad de inversiones públicas para financiar los procesos de innovación. La tecnología ya no es vista como un bien público, neutral y exógeno, que puede ser absorbida por cualquier concurrente atento a la señales del mercado.

Pero ninguno de estos agregados, sutilezas o complementos ha modificado las conclusiones regresivas del neoliberalismo. Estos corolarios se mantienen tan invariables, como las convocatorias a garantizar los negocios de los poderosos. La prioridad de políticas «amigables» hacia el capital mediante aperturas comerciales, privatizaciones y flexibilidad laboral no ha cambiado. El mismo recetario persiste con un nuevo envase de presentación.

\section{Variedad de sentidos}

Al comienzo del siglo XXI el neoliberalismo perdió la homogeneidad que caracterizó a su debut. El término adoptó múltiples connotaciones y la definición previa de ofensiva del capital sobre el trabajo quedó referida a cuatro problemas específicos.

En primer lugar existe una interpretación de este fenómeno como nueva etapa del capitalismo. Esta acepción alude al período transcurrido desde los años los 80 hasta la actualidad a escala global. La peculiaridad de América Latina en esta fase ha sido su inserción internacional como proveedora de materias primas.

El neoliberalismo aporta la justificación de este modelo exportador con primacía agro-minera, pilares extractivistas, fabricación maquiladora y servicios transnacionalizados. Todos los gobiernos de la región comparten este patrón de reproducción primario-exportador.

Un segundo sentido del neoliberalismo reúne a los países que han optado por estrategias de libre-comercio. México lidera este pelotón desde la suscripción del NAFTA con Estados Unidos y Canadá hace 20 años. Su economía ha quedado moldeada por las consecuencias de un tratado que reforzó la integración del país a la potencia del norte, como proveedor de petróleo y mano de obra barata. 
Pero el ambicioso proyecto estadounidense de forjar un mercado hemisférico para las grandes empresas (ALCA) se frustró. Las resistencias populares, la disconformidad de ciertos sectores empresarios y el rechazo de los gobiernos más autónomos alineados con el MERCOSUR neutralizaron ese intentó en el 2005 (Cumbre de Mar del Plata).

Desde ese momento la promoción imperial de un gran tratado de libre comercio ha quedado sustituida por convenios bilaterales suscriptos con los gobiernos más afines. Varios TLC se consolidaron, otros se demoraron y algunos quedaron bloqueados. Pero un enjambre de acuerdos ya enlaza a Estados Unidos con el grueso de la región centroamericana y con varios países del sur (Chile, Colombia o Perú).

En los últimos años Obama retomó la ofensiva para introducir un convenio general de libre-comercio (Tratado del Pacífico), tendiente a gestar cierta triangulación mundial con Europa y Asia. También las firmas europeas impulsaron sus propias negociaciones e intentan erosionar el MERCOSUR forjando acuerdos unilaterales con Brasil (Hagman, 2014).

Las mismas tratativas de Europa con Ecuador apuntan a extender el sometimiento comercial que ya impera en Perú o Colombia. En el caso de Uruguay las negociaciones incluyen un drástico compromiso de apertura comercial y equiparación de los proveedores nacionales del Estado con sus competidores externos (León, 2014; Elías, 2014).

Esta oleada de presiones no sólo recrea las rivalidades entre europeos, estadounidenses y chinos por el control de los recursos naturales de la región. El libre comercio es un mecanismo de la mundialización que promueven todas las potencias. Cuanto más elevado sea el número de convenios suscriptos por la región, mayor será su subordinación a un modelo que bloquea el desarrollo latinoamericano.

La tercera acepción del neoliberalismo alude a una política económica de ortodoxia monetaria, fiscal y cambiaria con variantes monetaristas y ofertistas. Pero la crisis global del 2008 ha generado importantes cambios en esta práctica. Muchos neoliberales olvidaron los principios de riesgo y competitividad y justifican los auxilios estatales a los bancos.

Esta adaptación pragmática al temblor financiero no presenta hasta el momento la magnitud observada en las economías centrales. La región no padeció desmoronamientos bancarios, ni explosiones de endeudamiento. Persiste el ascenso de los precios de las commodities (en forma atenuada) y también la afluencia de inversiones extranjeras. Por esta razón se implementan políticas contra-cíclicas de gasto público e impulso al consumo. Los ministros neoliberales han recurrido a 
estas recetas con el mismo fervor que sus adversarios heterodoxos, especialmente en Chile, Colombia, México o Perú.

Ciertamente existe un tipo de política económica singular del neoliberalismo que se contrapone al patrón keynesiano. El signo determinante de esta orientación no es la gravitación del Estado, sino la jerarquía asignada a las privatizaciones, la apertura comercial y la flexibilización laboral. También se prioriza el gerenciamiento privado y las inversiones extranjeras como sustitutos del ahorro interno.

¿Cuáles son los intereses sociales favorecidos por esa política? Es evidente que beneficia a los capitalistas en desmedro de los trabajadores, pero no es tan nítido su apuntalamiento de sectores burgueses específicos. Algunos autores subrayan las ventajas obtenidas por los rentistas financieros y otros resaltan el sostén general de los grupos concentrados (Salama, 1998; Martins, 2005).

Es evidente que el neoliberalismo mejoró inicialmente el perfil de los sectores financieros y afianzó posteriormente los negocios agro-mineros volcados a la exportación. Ha obstruido, en cambio, los procesos de acumulación de las fracciones industriales más dependientes del mercado interno.

\section{Evaluaciones combinadas}

El cuarto sentido del neoliberalismo es su dimensión política. En este plano se identifica con los gobiernos derechistas subordinados a Estados Unidos, que recurren a la represión para apalear la protesta popular. Es la estrategia elegida por el PAN y el PRI que ensangrentaron a México en una guerra social bajo la cobertura de «erradicar el narcotráfico». También aquí se ubican los mandatarios de Colombia que acumulan un récord de persecuciones y asesinatos de luchadores sociales.

En ese mismo campo deben ser situados los presidentes de Perú que privilegian la respuesta represiva frente a las resistencias al extractivismo. Es la misma política que han seguido en Chile los líderes de la Concertación, manteniendo los pilares de la Constitución pinochetista. El uso de la fuerza es también un rasgo compartido por los presidentes privatistas de Centroamérica.

Todos estos gobiernos desarrollan agendas reaccionarias apuntaladas por los medios de comunicación. Priorizan especialmente la difusión de valores conservadores, para oponer a las clases medias con los sectores más empobrecidos.

Pero este neoliberalismo político ha perdido el empuje triunfalista que exhibía en los años 90. Sólo mantiene una gran capacidad para lanzar contraofensivas. En los últimos años recurrió al golpismo con disfraz institucional, para derrocar a un 
presidente tibiamente reformista en Paraguay y para tumbar un mandatario aliado del chavismo en Honduras.

La derecha igualmente fracasó en las acciones destituyentes para desplazar a los presidentes de Venezuela y Bolivia. Esta incapacidad para imponerse en los principales países en disputa ilustra los límites de la reacción. Habrá que ver como impacta el reciente afianzamiento electoral de la derecha en Colombia, el giro conservador de varios gobiernos de centroizquierda y el resultado de importantes elecciones en curso.

El rumbo estadounidense es el principal condicionante de cualquier acción significativa del neoliberalismo regional. La primera potencia mantiene su influencia en la zona desplegando fuerzas militares en Colombia. El margen de intervención directa de los marines ha quedado recortado, pero la función geopolítica de América Latina para el imperio no ha cambiado. En la nueva realidad de UNASUR y CELAC el imperio ensaya distintos caminos para restablecer su injerencia.

El neoliberalismo regional debe ser analizado evaluando esta variedad de procesos. Presenta cuatro dimensiones diferenciadas como etapa, estrategia de libre-comercio, política económica y gobiernos derechistas. Es muy importante distinguir esos niveles a la hora de establecer un balance.

A diferencia de otras regiones no hay respuesta simple para definir si el modelo derechista se encuentra a la ofensiva o en repliegue. Existen varios gobiernos en conflicto con este curso y se han obtenido triunfos populares que limitaron su predominio. Pero todas las administraciones actuales comparten el mismo patrón primario exportador de inserción en la mundialización neoliberal.

Un gobierno derechista se amolda por completo al rumbo neoliberal, otro de centroizquierda no se aviene fácilmente a ese sendero y los procesos radicales chocan con sus fundamentos. En un caso prevalece la sintonía, en otro la convivencia y en un tercero la contraposición.

Esta desincronización deriva en última instancia del impacto generado por rebeliones populares victoriosas, que limitaron el alcance regresivo del neoliberalismo sin sepultarlo. Introdujeron grandes transformaciones políticas que incidieron en forma muy limitada sobre la esfera económica. Por esta razón es erróneo suponer que América Latina ha ingresado en una fase «pos-liberal». Ese giro supondría que toda la etapa de las últimas tres décadas ha quedado atrás y hasta ahora ese viraje no se consumó. 


\section{Libre-comercio y globalización}

Los neoliberales contemporáneos retoman la vieja caracterización del libre-comercio como llave maestra del desarrollo. Afirman que es la manera más directa de reducir la pobreza y la inequidad.

Pero olvidan que la implementación de este principio en América Latina desembocó en la primacía de exportaciones agro-mineras e importaciones industriales. Esa asimetría condujo al subdesarrollo y a la inserción dependiente en el mercado mundial.

Los defensores del libre-comercio ignoran esta trayectoria histórica. Olvidan que Inglaterra optó por esa estrategia cuando ya era dominante a escala mundial. Tampoco recuerdan que el comercio irrestricto fue evitado por Estados Unidos, Japón o Alemania en el debut de su desenvolvimiento industrial. Sólo aceptaron parcialmente esa orientación cuando lograron alta productividad en los sectores sujetos a la competencia global (Bairoch, 1997, p. 227, 228, 234).

Todas las economías desarrolladas impusieron normas de libre-comercio a la periferia para asegurar la colocación de sus exportaciones industriales. Lejos de constituir un instrumento de prosperidad para las naciones atrasadas, esa apertura introdujo obstáculos a la diversificación económica y al crecimiento de la periferia. América Latina padeció el fortalecimiento de las oligarquías rentistas y el bloqueo a la acumulación sostenida de capital.

Los neoliberales contemporáneos retoman las viejas críticas al proteccionismo, señalando que impide aprovechar las ventajas comparativas de cada país. Sitúan esas conveniencias en la agricultura o en la minería, como si América Latina cargara con un mandato divino de provisión de materias primas a los países desarrollados.

No registran el evidente beneficio que aportó ese status internacional a las economías ya industrializadas y la adversidad que impuso a las naciones periféricas. Mientras que el primer tipo de países pudo desenvolver intensos procesos de expansión fabril, el segundo grupo quedó relegado a un estadio básico de exportador primario.

Es absurdo suponer que cualquier economía puede mejorar su perfil, reforzando su colocación «natural» en la división internacional del trabajo. El desarrollo exige lo contrario: lidiar con la adversidad de los condicionamientos externos.

Ningún país latinoamericano puede convertirse espontáneamente en una economía avanzada, sin modificar la matriz histórica que obstruyó su desenvolvimiento 
productivo. Esa estructura genera transferencias de recursos hacia los países desarrollados y reproduce distintas modalidades del atraso (Osorio, 2009, p. 37-40).

Las ingenuidades librecambistas perdieron influencia durante la segunda mitad del siglo pasado con la industrialización de México, Brasil y Argentina. Pero las limitaciones y fracasos de los modelos de sustitución de importaciones reavivaron las creencias previas en los beneficios de la apertura comercial.

Esas ilusiones han encontrado un nuevo techo. Los efectos devastadores de la desprotección padecida por América Latina en las últimas dos décadas afectaron seriamente la credibilidad de los mitos libre-cambistas. Salta a la vista cómo la disminución de las tarifas aduaneras desmorona a las industrias locales, frente al aluvión de importaciones fabricadas en el exterior.

Los neoliberales igualmente realzan los beneficios de la globalización. Afirman que la apertura de las fronteras para la circulación del capital favorecerá a las economías relegadas, al inducir una traslación de fondos desde los países con altas dotaciones de capital hacia las economías subdesarrolladas.

Pero si esa tendencia fuera tan dominante ya habría irrumpido en el pasado. La existencia de un mercado mundial no es una novedad del siglo XX. Arrastra varias centurias de experiencias que nunca derivaron en equilibrios de la acumulación.

\section{Teorías de la convergencia}

El desenvolvimiento capitalista no está regulado por sencillos movimientos de capitales excedentes hacia los países empobrecidos. Es pura ensoñación suponer que las empresas transfieren espontáneamente fondos de Suiza hacia el Congo o de Alemania hacia Ceylán, en escenarios de capitales sobrantes en un polo y faltantes en el otro.

El sistema se reproduce siguiendo otros patrones de rentabilidad determinados por múltiples factores. La localización del capital es definida por los costos, los mercados y las expectativas en el comportamiento de las monedas, las tarifas o los salarios.

La fantasía globalista supone que esa compleja estructura histórica del capitalismo ha quedado abruptamente disuelta por el afianzamiento de idearios neoclásicos. Transforman esos imaginarios en realidades normativas que nadie logra corroborar (Lipietz, 2013).

Es cierto que la liquidez global fluye con más rapidez e intensidad que en el pasado, pero de la mano de empresas transnacionales que relocalizan su producción en ciertas 
regiones ya enlazadas con el capital global. Sólo en esas condiciones usufructúan de la baratura, el adiestramiento o el sometimiento de la fuerza de trabajo.

Pero tampoco esos movimientos equiparan los acervos nacionales de capital. Generan fracturas y polarizaciones que segmentan al capitalismo en un nuevo orden de perdedores y ganadores, con centros, semiperiferias y periferias.

El esquema de las ventajas comparativas desconoce la existencia de obstáculos elementales al logro de equilibrios mundiales. Ignora la nueva secuencia de polaridades que caracteriza a cualquier reorganización del mercado global. Un hipotético curso de aproximación de África Sub-sahariana con Europa del Norte o de Centroamérica con Estados Unidos generaría fracturas de mayor alcance que las brechas a reducir. Estos desniveles serían propios de la acumulación y obstruirían los empalmes que imagina la teoría neoclásica.

El librecambismo neoliberal promueve políticas reaccionarias con supuestos banales. Reivindica la desigualdad social, celebra la mercantilización de la acción humana, glorifica el consumismo e incentiva un ejercicio despiadado de la competencia individualista.

También afirma que la revolución de las comunicaciones achicó el planeta, facilitando la concreción del ideal neoclásico de un mercado perfecto. Supone que una vez reducidas las barreras interpuestas por los estados nacionales, nada impedirá la plena circulación del capital, la transparencia total y la asignación óptima de los recursos a escala mundial.

En estas condiciones el libre-comercio aseguraría el desarrollo, al erradicar las trabas que en el pasado obstruyeron la movilidad del capital y del trabajo. Los economistas más ortodoxos (Barro, Sala I Martin, Williamson) y sus instituciones (FMI, Banco Mundial) recurren a esa teoría de la convergencia global, para justificar su promoción de políticas de apertura.

Pero esas afirmaciones no aportan ninguna novedad al conocido libreto de los rendimientos decrecientes en el centro, que deberían incentivar el despegue de la periferia. En esta hipótesis de convergencias entre economías atrasadas y adelantadas se inspiraron todas las teorías metropolitanas del desarrollo (Weeks, 2001; Arrighi, Korzeniewicz, Consiglio \& Moran, 1996).

Durante décadas los neoclásicos ensayaron una «econometría de la convergencia», para intentar corroborar el achicamiento de las brechas estructurales entre el centro y la periferia. Pero con gran frecuencia esos estudios confundieron movimientos financieros coyunturales con tendencias de largo plazo. 
Además construyeron modelos muy arbitrarios, atribuyendo el secreto del empalme global al comportamiento virtuoso de cierto factor (educación, tecnología, gestión). Aislaban ese elemento de la dinámica general de la acumulación buscando demostrar la preeminencia de tendencias hacia la equivalencia global. Pero estos procesos sólo se verificaban en la nebulosa de un razonamiento abstracto.

Frente a las inconsistencias de ese procedimiento algunos teóricos neoclásicos optaron por introducir una tesis sustituta de «convergencia condicional». Postularon únicamente el empalme entre países con parámetros tecnológicos, institucionales o legales similares.

Pero con esta enmienda diluyeron los interrogantes a dilucidar. Ya no se supo quién converge y cuál sería la explicación de ese proceso. Al introducir una restricción más acotada abandonaron de hecho el presupuesto previo. Recurrieron a una hipótesis de «segundo mejor», para exponer tautologías de convergencias entre economías que ya empalmaban previamente (Moncayo, 2004).

\section{Raíces ideológicas regionales}

El pensamiento neoliberal contemporáneo combina fundamentos económicos neoclásicos con actualizaciones de la historiografía liberal. Esta concepción nutrió la ideología de las clases dominantes latinoamericanas desde la Independencia hasta la crisis de 1930. Recreó los mitos del colonialismo y retomó todos los supuestos de superioridad del colonizador europeo sobre los indígenas y los esclavos.

Las versiones más básicas de esa teoría repitieron los prejuicios iniciales propagados por los conquistadores de América. Esos enfoques concebían al nuevo continente como una región estructuralmente atrasada por la gravitación de imperativos climáticos adversos. Suponían que esos condicionamientos impedían a los nativos desenvolver la agricultura y el comercio. Por eso postulaban superar la barbarie regional con un padrinazgo externo.

Durante tres siglos esta concepción difundió creencias de supremacía occidental. Divulgó la imagen de un nuevo continente dotado de excepcionales riquezas y pobladores incapacitados para aprovecharlas. Europa quedó identificada con la introducción de la civilización en un continente previamente divorciado de la historia humana.

Con estas ideas colonialistas se justificó la explotación impuesta a los pueblos originarios. El indio era sinónimo de salvajismo y su evangelización era presentada como un correctivo de ese primitivismo. Esa redención incluía el trabajo servil en las minas y en todas las haciendas creadas a partir de la usurpación de las tierras comunales. 
Estos mismos preceptos fueron utilizados para introducir esclavos africanos en las regiones con poblaciones originarias diezmadas. La brutalidad de estas prácticas era maquillada con mensajes de padrinazgo tutelar sobre las razas inferiores (Chavolla, 2005, p. 42-53, 55-66, 72-74).

El pensamiento radical del siglo XIX confrontó con estas teorías de glorificación colonial. Pero el liberalismo conservador de las oligarquías criollas retomó todos los diagnósticos de incapacidad de los nativos. Estos principios fueron utilizados por los terratenientes y comerciantes locales para afianzar su dominación. Con esos pilares gestaron naciones formalmente soberanas y económicamente dependientes del capitalismo británico.

La derrota de las corrientes democrático-radicales al concluir las guerras de la Independencia facilitó la consolidación de los prejuicios euro-centristas Aparecieron nuevas explicaciones que atribuían el subdesarrollo no sólo a la gravitación previa de culturas indígenas. También fue impugnado el débil liberalismo de la tradición española.

En ese contexto el desprecio por al retraso indígena fue combinado con cuestionamientos al proteccionismo hispánico. La fascinación por la cultura inglesa (y francesa) condujo al repudio de lo identitario y al rechazo de la propia singularidad mestiza de la región (Devés, 2005, p. 47-53).

La idealización del Viejo Continente se reforzó en todos los planos. Europa fue identificada con la racionalidad y el desarrollo de la ciencia. Con este bagaje de creencias se promovió la incorporación de los países latinoamericanos a un desenvolvimiento guiado por la locomotora europea. Estos mismos principios alimentaron la ideología positivista de la modernización.

El liberalismo se amoldó a las necesidades de las oligarquías agro-mineras. Justificó el incremento de sus fortunas y la instrumentación de un esquema de exportación de materias primas, a cambio de manufacturas provistas por la industria británica.

Las teorías librecambistas convalidaron el ahogo de la estructura productiva local y facilitaron la apropiación oligárquica de las rentas de la región. Fueron ideas muy persistentes hasta las primeras décadas del siglo XX. Presentaban los intereses de las minorías privilegiadas como conveniencias comunes de toda la sociedad latinoamericana.

Estas miradas perdieron influencia a partir de la gran depresión, pero resurgieron en los años 50-60 a través de nuevas teorías del desarrollo. La fascinación con el ejemplo europeo fue sucedida por el deslumbramiento con el modelo norteamericano. 
Derecho ₹ Realidad

Mediante grandilocuentes llamados a la modernización se convocó a sustituir los patrones rutinarios de conducta por nuevos valores de riesgo, inversión y competencia. Se afirmó que ese cambio de costumbres encarrilaría a Latinoamérica por la senda del desarrollo (Marini, 2007).

El salto de la pobreza hacia el bienestar, el consumo en gran escala y el trabajo especializado solamente requería insertar a la región en el despegue modernizador. El teórico estadounidense Rostow aportó los fundamentos de este guión. Utilizó también ese mensaje para contener la amenaza revolucionaria. El nuevo programa era motorizado por asesores del Departamento de Estado que intervenían activamente en la guerra fría y difundían sus concepciones como antídotos del comunismo (Bustelo, 1998, p. 139-143).

\section{Contradicciones de todo tipo}

Desde los años 70-80 el neoliberalismo latinoamericano amalgamó viejas tradiciones de elitismo regional con un proyecto de ofensiva thatcherista. La hostilidad al estatismo (pre-colombino, colonial, pos-independentista o nacionalista) reapareció con nuevos discursos de demonización del estado.

La crítica al intervencionismo hispánico y a la idiosincrasia pasiva de los pueblos originarios se transformó en objeciones a la ausencia de competencia, en sociedades subordinadas al despotismo de los funcionarios. Resurgieron los cuestionamientos al agobio que impone la burocracia a la vida de los ciudadanos.

Estos mensajes resumen el libreto neoliberal contemporáneo. Despotrican contra el estado omnipresente, que impide desenvolver los negocios creados por los individuos. Convocan a eliminar esa opresión estimulando a las personas a valerse por sí mismas, con el mismo ingenio e individualismo que florecen en los países exitosos.

Pero esta visión omite que el Estado no es tan adverso a los capitalistas. Solventa activamente el enriquecimiento de los poderosos y convalida el desamparo de los desprotegidos. Nunca abandona a los dominadores a su propia suerte, ni asegura la subsistencia de los desamparados.

Los neoliberales atribuyen el atraso latinoamericano a ciertas estructuras culturales internas. Explican siglos de estancamiento regional y resignación frente al paternalismo estatal por la ausencia de un talante competitivo anglo-sajón.

Pero olvidan mencionar que el liberalismo fue la ideología constitutiva de las naciones latinoamericanas y que sus parámetros definieron el modelo agro-exportador 
prevaleciente desde mediados del siglo XIX. Al atribuir la falta de progreso a la inferioridad cultural de la zona, no explican como persistió esa tara en sociedades regidas por principios liberales. Suponen que las elites encarnaron ese espíritu mercantil frente a mayorías populares afectadas por el atontamiento estatista.

La versión actual de esa mirada aristocrática se concentra en la crítica al virus del populismo. La influencia de esta enfermedad es explicada por la conducta facilista que adoptan los funcionarios, para asegurarse el sostén de sus clientelas electorales. Imponen una dependencia de los votantes hacia el estado que frustra la preeminencia del mercado y recrea el estancamiento.

Pero también aquí omiten recordar a los grupos capitalistas beneficiados por este tipo de administración. En ese ocultamiento se fundamenta el hipócrita palabrerío que despliegan contra el gigantismo estatal. Proponen erradicar esa atrofia mediante la instalación de un «estado mínimo», que se desenvolvería mejorando la eficiencia del gasto y la eficacia de los funcionarios (Mols, 1995).

Este mensaje suele olvidar que el neoliberalismo ya arrastra varias décadas de administración estatal y que en ningún lado ha logrado alcanzar esa meta de eficacia. A veces justifican este fracaso afirmando que la mayoría de las experiencias gubernamentales «no han sido genuinamente liberales». Contrastan lo vivido con un ideal de pureza mercantil-competitiva que no existe en ninguna parte del mundo.

Pero lo más curioso de ese argumento es su complementaria impugnación del socialismo. Afirman que este proyecto es una «utopía irrealizable» cuando su propio modelo navega en la fantasía.

El neoliberalismo actual retoma también la teoría de la modernización como explicación de las dificultades afrontadas por el empresariado latinoamericano para desplegar sus potencialidades. Atribuye esa frustración a la preeminencia de patrones culturales tradicionales, que obstruyen el surgimiento de los valores característicos del emprendedor contemporáneo. Estiman que esas capacidades empresariales están presentes, pero no logran emerger en el agobiante clima de estatismo latinoamericano (Reyes, 2001).

Una idealización extrema de este individualismo empresario fue introducida en las últimas décadas por talibanes del neoliberalismo como Carlos Alberto Montaner, Martín Krause y especialmente Hernando de Soto. Presentan a los empobrecidos cuentapropistas como ejemplos de resurrección de la iniciativa privada. Afirman que los comerciantes precarizados del circuito informal han comenzado a liberar a la economía del estatismo, con acciones de racionalidad mercantil en universos de genuina competencia. 
Pero esta exaltación de los desamparados como exponentes del ideal capitalista constituye una verdadera confesión de los resultados del neoliberalismo. Este esquema expropia a los trabajadores, expulsa a los campesinos de sus tierras y empobrece a las clases medias hasta desembocar en la miseria que padece América Latina.

Lo más insólito de la argumentación neoliberal es su enaltecimiento de estos efectos. Aunque atribuye la precarización al intervencionismo estatal, es evidente que la informalidad es consecuencia directa de un modelo que destruye empleos, mediante privatizaciones y aperturas comerciales. Sus artífices idealizan las desgracias causadas por la flexibilización laboral.

Las caricaturas de los empobrecidos como agentes transmisores de la mano invisible tuvieron cierto eco en el debut del neoliberalismo. Pero han perdido influencia en la última década, a medida que el empobrecimiento potenció la fractura social, masificó la delincuencia y acrecentó las tensiones de la marginalidad.

Este terrible escenario induce a la mayoría de los neoliberales a sustituir los elogios de la informalidad por la promoción de programas masivos de asistencialismo. Con teorías de auxilios transitorios («hasta que el mercado genere empleo privado») han incluido este tipo de gastos sociales en sus políticas de gobierno. Las administraciones derechistas destinan importantes erogaciones presupuestarias a contener la rebeldía que genera su modelo.

\section{Una ideología de la dominación}

La idealización del empresario es un pilar de la vertiente austríaca de la economía neoclásica, que se gestó con Menger y Bohm Bawerk y se afianzó con Von Mises y Hayek. Sus voceros propician la ampliación de las desigualdades sociales, la subordinación de la democracia a la propiedad y el reforzamiento de la supremacía irrestricta del mercado. Reivindican modalidades extremas de competencia, argumentando que aleccionan al consumidor y alientan la innovación del empresario.

A diferencia de la corriente walrasiana reconocen el carácter incierto de la inversión, la imperfección de la racionalidad individual y la fragilidad de las preferencias de los consumidores. Pero no deducen de estas dificultades ninguna propuesta de regulación de los mercados. Al contrario, proponen liberar el juego de la oferta y la demanda de cualquier interferencia, subrayando el carácter benéfico del orden mercantil y el efecto positivo del darwinismo social.

Con este tipo de concepciones, el neoliberalismo ha desenvuelto una influyente ideología en todos los sentidos del término. Aporta ideas que naturalizan la opresión 
para orientar la acción de los dominadores. Como creencia, cosmovisión o legitimación del grupo dominante, el neoliberalismo constituye un credo de gran peso para el funcionamiento actual del capitalismo (Eagleton, 1997, p. 19-57, 275279).

Es una ideología con fundamentos racionales que a su vez propaga sistemáticos engaños. Promueve ilusiones en el reinado del mercado y en la existencia de oportunidades para todos los individuos. Oculta la apabullante preeminencia de las grandes empresas y el estructural afianzamiento de la explotación. Difunde el mito de la obstrucción estatista del desarrollo latinoamericano, omitiendo la dependencia y la inserción primarizada de la región en el mercado mundial.

El neoliberalismo expande estas ideas al servicio de las clases dominantes. Sintetiza las conveniencias de los grupos privilegiados de América Latina. En el pasado expresaba los programas de los terratenientes exportadores y en la actualidad canaliza las demandas de los grandes bancos y las corporaciones agro-industriales con negocios internacionalizados.

Las ideas liberales son creencias colectivas propagadas por las clases capitalistas. Forman parte del pensamiento latinoamericano desde que esa cosmovisión emergió para cohesionar a las minorías opresoras. En las últimas décadas provee todos los argumentos que utiliza al establishment para justificar su primacía. Los pilares de esas creencias (modernización, progreso, imitación de Occidente) inciden en la subjetividad de los individuos educados en las reglas de la mitología liberal.

El grado de penetración de esas ideas entre los oprimidos es un tema de gran controversia. Aunque el liberalismo tuvo momentos de gran influencia social, siempre fue una concepción explícitamente hostil a los intereses, tradiciones y deseos de los explotados. Por esta razón nunca fue plenamente interiorizada por este sector. Logró cierta incidencia entre fines del siglo XIX y 1930, pero quedó estructuralmente relegada con la industrialización de posguerra y la expansión del nacionalismo.

Ha retornado en las últimas décadas de oleada neoliberal pero sin echar raíces en la mayoría de la población. Las resistencias y victorias parciales logradas contra la ofensiva derechista han limitado la gravitación de sus conceptos, abonando las teorías que remarcan la acotada penetración de las ideologías dominantes entre los sectores populares (Abercrombie, Hill \& Turner, 1987; Therborn, 1987)).

Pero el liberalismo tradicional no es el único formato de esa concepción. También existen otras modalidades más sofisticadas que requieren evaluaciones específicas. Estas vertientes conforman el social-liberalismo que analizamos a continuación. 
Derecho ₹ Realidad

\section{Referencias}

Abercrombie, N., Hill, S. \& Turner, S. (1987). La tesis de la ideología dominante. Madrid: Siglo XXI.

Anderson, P. (1995.1996). Balance del neoliberalismo: lec-ciones para la izquierda. El Rodaballo, (3).

Anderson, P. (2003). Neoliberalismo: un balance provisorio. En La trama del neoliberalismo. Mercado, crisis y exclusión social. Buenos Aires, Argentina: CLACSO.

Anderson, P. (2009). The New Old World. London: Verso.

Arrighi, G., Korzeniewicz, R., Consiglio, D. \& Moran, T. (1996). Modeling zones of the world economy. In Annual Meeting of the American Sociological Association.

Bairoch, P. (1999). Mythes et paradoxes de 1'histoire economique. La découverte, 7, 227-228, 234.

Burkett, P; Hart-Landsberg, M. (2003). A critique of catch-up theories of development. Journal of Contemporary Asia, 33(3).

Bustelo, P. (1998). Teorías contemporáneas del desarrollo económico. Madrid: Síntesis.

Chavolla, A. (2005). La imagen de América en el marxismo. Buenos Aires: Prometeo.

Devés, E. (2005). El pensamiento latinoamericano en el siglo XX: entre la modernización y la identidad, Tomo III. Buenos Aires: Biblios.

Eagleton, T. (1997). Ideología. Barcelona: Paidós.

Elías, A. (2014). Por qué Uruguay solicitó integrarse al TISA. Recuperado de alainet.org/active

Guillén, A. (2007). La teoría latinoamericana del desarrollo. Repensar la teoría del desarrollo en un contexto de globalización. Buenos Aires: CLACSO.

Hagman, I. (2014). Un nuevo Alca se negocia en silencio. Recuperado de ww.rcci.net/globalizacion/

Harvey, D. (2013). El neoliberalismo como proyecto de clase. Recuperado de vientosur.info/ 
Harvey, D. (2005). A brief history of Neoliberalism. New York: Oxford University Press.

Herrera, R. (2010). El renacimiento neoliberal de la economía del desarrollo. En Globalización, dependencia y crisis económica. (pp 23-24). Málaga: FIM.

Hirsch, J. (1999, mayo). Globalización del capital y la transformación de los sistemas de estado. Cuadernos del Sur, (28).

Katz, C. (2008). El rediseño de América Latina, Alca, Mercosur y Alba. Buenos Aires: Ediciones Luxemburg.

Katz, C. (2008). Las disyuntivas de la izquierda en América Latina. Buenos Aires: Ediciones Luxemburg.

Katz C. (2014, junio). Transformaciones de la era neoliberal. Realidad Económica, (284).

León, M. (2014). Ecuador: Acuerdo con la Unión Europea: ¿Una capitulación inevitable? Recuperado de alainet.org/active

Lipietz, A. (2013, fevrier). Pour un protectionnisme universaliste. Rétabli lipietz.net

Moncayo, E. (2004, sep.). El debate sobre la convergencia económica internacional e interregional: enfoques teóricos y evidencia empírica. Economía y Desarrollo, 3(2).

Marini, R. M. (2007). La sociología latinoamericana: origen y perspectivas. En Proceso y tendencias de la globalización capitalista. Buenos Aires: CLACSOPrometeo.

Mols, M. (1995). Sobre el estado en América Latina. En El estado en América Latina. Buenos Aires: Ciedla.

Nahon, C., Rodríguez, C. \& Schorr, M. (2006). El pensamiento latinoamericano en el campo del desarrollo del subdesarrollo: trayectorias, rupturas y continuidades. Recuperado de www.idaes.edu.ar/papelesdetrabajo/paginas

Olivera, M. (2010). Las teorías del desarrollo desde la posguerra al nuevo milenio. En Globalización, dependencia y crisis económica (pp 26-27). Málaga: FIM.

Osorio, J. (2009). Explotación redoblada y actualidad de la revolución. México: ITACA-UAM.

Reyes, E. (2001). Principales teorías sobre desarrollo económico y social. Recuperado de www.ucm.es/info/nomadas 
Salama, P. (1998, 2do sem.). Las nuevas causas de la pobreza en América Latina. Ciclos, (16).

Martins, C. A. (2005). Neoliberalismo e desenvolvimento na America Latina. En La economía mundial y América Latina. Buenos Aires: CLACSO.

Therborn, G. (1987). La ideología del poder y el poder de la ideología. Madrid: Siglo XXI.

Vidal, G. \& Guillen, A. (2007). La necesidad de construir el desarrollo en América Latina. En Repensar la teoría del desarrollo en un contexto de globalización. Buenos Aires: CLACSO.

Weeks, J. (2001). The expansion of capital and uneven Development on world Scale. Capital and Class, (74). 